\title{
Britain wrestles with EC rule on modified organisms
}

London. British lawmakers are trying to incorporate both a desire for openness and the preservation of patent rights into an interpretation of two directives from the European Commission on genetically modified organisms. Biotechnology companies are concerned that the directives, which were supposed to become law a year ago, will discourage research and compel the release of information that could invalidate patent applications.

The directives, which cover the contained use and release of these organisms, say that the commercial value and intellectual property of researchers will be preserved but that information about the organism and its proposed use must be circulated within the European Communities and made public in the host country, probably through accessible registers. The only permanent solution would be to change the directives, a time-consuming process involving considerable loss of face on the part of the commission and one that seems unlikely in the current political climate. Another option is to change the patent laws, but this would require agreement by each member of the EC. Several countries, including France and the Netherlands, intend to implement regulations that follow the

directive, while Denmark makes the information available already.

Although the regulations were revised earlier this year after lobbying by the biotechnology community, the current draft has retained strict requirements about disclosure. Industry is concerned that the rules would lead companies to reduce or abandon promising research or force them to shift operations to countries without such rules. University researchers also fear losing intellectual property rights over their work.

In the coming weeks, the Department of the Environment (DOE) and the Health and Safety Executive (HSE) will try to strike a balance between protecting property rights and ensuring the public's right to know about such experiments. It is hoped that the regulations will be ready for Parliament by the end of the year.

One solution is for researchers to submit two sets of information, one giving full details of the work on which the DOE and HSE could grant or deny permission to go ahead, and another for inclusion on public registers. However, the balance between the two sets would be delicate, and researchers may not want to wait until their patent is rejected to learn whether they have given too much away.

Ian Mundell

\section{Overregulation could damage US biotechnology, says report}

San Francisco. Existing US regulations for field tests of genetically engineered organisms are stifling research, according to a new report by the National Biotechnology Policy Board that recommends strict regulation of deliberate releases only for products posing the greatest risk to public safety.

The document emphasizes the social costs of regulatory delays and recommends a pilot study to measure the benefits of new products. This practice would help to quantify the impact of regulatory delays, provide data about the safety of new products, educate the public about the potential of biotechnology and reward federal agencies for prompt review, says the report, which was approved last week by the policy board at its meeting in Washington, DC. The board is a 20 -member body formed by the National Institutes of Health in 1989 at the direction of the US Congress to review government activities relating to biotechnology.

The board's recommendations follow a study by the congressional Office of Technology Assessment that warned regulators not to relax biotechnology regulation so much that public concerns are ignored. But the report points out that "intense government oversight tends to confirm public perceptions that biotechnology processes pose significant and unique dangers".

The head of the biotechnology programme at the US Department of Agriculture (USDA) criticized the report for emphasizing the negative aspects of regulations. "I believe that good regulations not only assure safety but also help to facilitate technology transfer and development", says the USDA's Terry Medley, whose office is expected shortly to release its proposal for somewhat relaxed field-testing rules. At the same time, microbiologist Rita Colwell, president of the Maryland Biotechnology Institute in Baltimore, defended the report for endorsing the importance of field testing.

The report also recommends financial incentives for the industry, including government participation in joint ventures, technology transfer from universities with patent rights attached in some cases and changes in the US tax code that would encourage investment in research.

Sally Lehrman

\section{Brian Henderson named president of Salk Institute}

Washington. Brian Henderson, a 55-yearold cancer epidemiologist and director of the Kenneth Norris Jr Comprehensive Cancer Center at the University of Southern California (USC), has been appointed president of the Salk Institute, with effect from February 1993. The announcement, to be made this week, marks the end of a debilitating four-year international search for a successor to Frederic de Hoffmann as head of the private institute, founded in

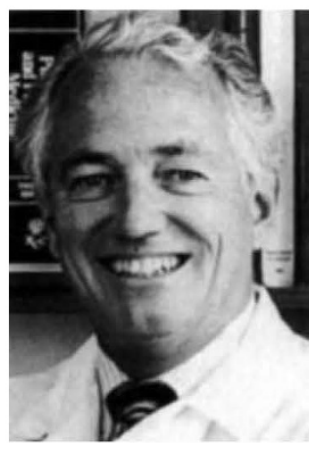

Brian Henderson 1960 by Jonas Salk as a centre for basic research relevant to human disease.

In choosing Henderson, the institute sought a president who could work well with the institute's 225 researchers, increase its $\$ 27-\mathrm{milli}$ on endowment (relatively small for an institution with an annual budget of $\$ 40$ million) and oversee growth in faculty after a sizeable expansion of the institute is completed over the next few years. It also wanted someone to educate the community about the importance of basic science "so people will see that the work we're doing here affects health", says Stephen Heinemann, faculty chairman.

Renato Dulbecco, who was appointed acting president and then actual president after de Hoffmann resigned in 1988 because of illness (he died the following year), has made some overtures to the community, but de Hoffmann did little to publicize the institute's mission during his 18-year tenure. Henderson hopes that references to his own work on genetic susceptibility to cancer will help to demonstrate the connection between basic research and health care, and he intends to continue an active research programme in epidemiology.

In the past few years, Salk has suffered the embarrassment of failed negotiations on the presidency with such well-known researchers as James Darnell of Rockefeller University and Arnold Levine of Columbia University, leading to public speculation that the institute's trustees were not equal to the task. In response, John Henry Felix, chairman of Salk's board of trustees, assumed responsibility for contract negotiations, a task that had previously been performed by a committee.

Traci Watson 